\title{
Targeting novel antigens in the arterial wall in thromboangiitis obliterans
}

\author{
Elif Guzel ${ }^{1}$, Ender Topal ${ }^{2}$, Ayse Yildirim ${ }^{3}$, Pergin Atilla ${ }^{4}$, Murat Akkus ${ }^{5}$ and \\ Attila Dagdeviren6
}

${ }^{1}$ Department of Histology and Embryology, Istanbul University, Cerrahpasa Faculty of Medicine, Istanbul ${ }^{2}$ Department of Cardiovascular Surgery, Dicle University Faculty of Medicine, Diyarbakir

${ }^{3}$ Department of Histology and Embryology, Mustafa Kemal University Faculty of Medicine, Hatay

${ }^{4}$ Department of Histology and Embryology, Hacettepe University Faculty of Medicine, Ankara

${ }^{5}$ Department of Histology and Embryology, Dicle University Faculty of Medicine, Diyarbakir

${ }^{6}$ Department of Histology and Embryology, Baskent University Faculty of Medicine, Ankara, Turkey.

\begin{abstract}
Thromboangiitis obliterans is an inflammatory disease possibly resulting from cigarette smoking as a primary etiologic factor, perhaps as a delayed type of hypersensitivity or toxic angiitis. As little is known about the pathogenesis of the disease, we aimed to determine novel antigens that might be responsible from the local inflammatory reactions and structural changes observed in this disease. An indirect immunoperoxidase technique is used to examine the tissue samples obtained from the dorsalis pedis artery of affected individuals with twenty monoclonal antibodies. Among these several antigens which are not previously reported in TAO like CD34, CD44 and CD90 were determined in the tissue samples examined. On the other hand, many other antigens like cytokine/chemokine receptors, several enzymes and leukocyte/lymphocyte antigens were lacking giving some clues about the local pathological reactions. We briefly discussed our findings for several critical antigens those first described in the present work, possibly having roles in the development of the disease. Expression of the CD90/CD11c receptor/ligand pair seems to play an important role in mononuclear cell recruitment to the damage site. Vascular invasion of not only tunica intima but also the tunica media in affected vessels is clearly demonstrated using endothelial cell specific antigens.
\end{abstract}

Key words: Thromboangiitis obliterans, TAO, Buerger's disease, vasculitis, immunohistochemistry, CD90, CD11c

\section{Introduction}

Thromboangiitis obliterans (TAO), or Buerger's disease, is a non-atherosclerotic segmental, thrombotic, inflammatory disease most commonly affecting the small and medium sized arteries and veins of the upper and lower distal extremities [1-4]. The disease was proposed in 1908 by Buerger [1]. Although the exact underlying cause of TAO is still unknown, the disease is strongly associated with tobacco abuse, implicating cigarette smoking as a primary etiologic factor $[3,5,6,7]$. Affected patients are mostly young male smokers, who develop ulcers and gangrene of the toes

Correspondence: A. Dagdeviren, Dept. of Histology and Embryology, Baskent University Faculty of Medicine, Ankara, Turkey; tel.: (+090312) 2341010,

e-mail: ddeviren@baskent.edu.tr and fingers as a result of the vascular ischaemia $[5,8]$. However, cases of women with TAO are becoming more common, coinciding with an increased incidence of smoking in this sex $[9,10]$. Although distal vessels of lower and upper extremities are the most commonly involved, other vessels such as cerebral, mesenteric, and coronary arteries can be rarely affected [11-14].

The diagnosis is based on characteristic clinical criteria as well as pathological findings in arteriography and histopathology; and there is no specific marker of the disease yet $[5,15]$. Acute Buerger's disease is characterized histopathologically by intensely cellular vessel wall inflammation, total luminal obliteration by the thrombus, together with a varying degree of recanalization; however, the internal elastic lamina and the overall vascular wall architecture remain preserved $[5,16]$. Cell infiltration was observed mainly in the thrombus and the intima. Macrophages expressing 
HLA-DR and dendritic cells are preferentially located in the intima and these cells may present antigens brought by the blood stream to CD4+ T lymphocytes predominating in the infiltrate $[17,18]$.

The pathogenesis of this disease is poorly understood and most hypotheses are controversial [4,7,16,18-20]. Accumulating clinical evidence point to an inflammatory and immunological pathogenesis. TAO is found to be associated with HLA-A9 and HLA-B5 antigens as well as polymorphism of the MICA gene [21,22]. A prothrombotic genetic factor was claimed to be associated with the risk of TAO [23]. Although most investigators speculate about an autoimmune mechanism, no direct causative antigen has yet been discovered [24,25]. However, an association between anticardiolipin antibodies and this disease was reported [26]. Antiendothelial cell antibodies were proposed to play a role in the pathogenesis of TAO [27]. Various studies were undertaken to examine the mechanism of the immune injury. An increased cellular and humoral response to collagen $[28,29]$, circulating immune complexes [30,31], elevated antielastin titers [32] and abnormal elastin degradation [33] were reported. The altered production of IL-6, IL12 and IL-10, the increased apoptosis as well as the elevated levels of circulating immune complexes were proposed to be the reason for the persisting immune inflammation in TAO [34]. The specificity of all these findings remains to be established.

As little is known about the pathogenesis of the disease we aimed to determine novel antigens that might be susceptible for the local reactions observed in this disease with the reference of previous reports. For this purpose we studied frozen sections of tissue samples from dorsalis pedis artery of affected individuals performing a screening using twenty monoclonal antibodies. Among these were several antigens which are not previously reported in TAO like CD34, CD44 and CD90. Some cytokine/chemokine receptors, several enzymes and leukocyte/lymphocyte antigens were also targeted. We discussed the findings indicating possible roles of these antigens or their absence in the development of the disease aiming to direct future studies including several novel antigens of yet unknown specificity.

\section{Materials and methods}

Specimens and sections. After obtaining an informed consent and receiving approval from the institutional Ethics Committee on human research, we have taken the tissue samples as partial biopsy specimens from Department of Pathology, Dicle University Faculty of Medicine from two patients who were both men and fulfilled all of Shionoya's clinical criteria for the diagnosis of Buerger's disease: (1) smoking history; (2) onset before the age of 50 years; (3) infrapopliteal arterial occlusions; (4) either upper limb involvement or phlebitis migrans; and (5) absence of atherosclerotic risk factors other than smoking [15]. Histopatho- logical diagnosis of both cases were confirmed by the same department.

The 43 year old patient had a smoking history of 13 years $(20$ $30 /$ day). There was gangrene in the big toe and necrosis on the tips of the 2nd and 3rd toes of his right foot. Big toe amputation and right lomber sympathectomy operations were performed, because there were no convenient distal arterial vessel detected with Doppler USG and conventional angiography for the arterial by-pass surgery. The part of the medial tarsal branch of the dorsalis pedis artery which was within the amputated tissue was used for the study. The other patient, 37 years old, had been a smoker for 9 years $(20 /$ day) prior to admission in our clinic. He was suffering from pain and redness in the left foot and critical ischemia (in the extreme) was observed on the big toe of his left foot when he was admitted to the clinic. Doppler USG and conventional angiography showed that the blood supply from the left popliteal artery was only by weak, thin collaterals in some parts. Because there was no convenient distal vessel for the arterial by-pass surgery, only left lomber sympathectomy and left big toe amputation were performed. The distal part of the dorsalis pedis artery within the amputated tissue was taken for the study also in this case.

Tissue samples from the dorsalis pedis artery of affected individuals were immediately frozen in liquid nitrogen, and stored in a liquid nitrogen tank for 2-3 days until sectioned. Cryo-sections (6$8 \mu \mathrm{m}$ thick) were taken with cryostat (Leica Frigocut 2800E, Wetzlar, Germany) on gelatin-coated slides and dried at room temperature. Then the sections were kept in humidity-free containers at room temperature until the staining was performed the day after.

Antibodies and staining procedure. In order to perform the screening, immunohistochemistry was performed using about twenty monoclonal primary antibodies which are all generated in mice including HI302, anti-vimentin, anti-CD10, anti-CD11c, anti-CD19, anti-CD20, anti-CD22, anti-CD34, anti-CD44, anti-CD62E, antiCD80, anti-CD90, anti-CD104, anti-CD106, anti-CD116, antiCD117, anti-CD123, anti-CD132, anti-CD195 and anti-TARC as listed in the Table 1 . The immunostaining procedure previously described is applied as follows [35]. Sections were fixed in acetone for 10 minutes and air-dried for at least 30 minutes. Sections were then incubated for 60 minutes at room temperature with monoclonal antibodies (mAbs) in a humidity chamber. The dilutions of the mAbs used in the study are also given in Table 1. For negative controls, primary antibodies were replaced by their non-immune isotypes. After washing in phosphate buffered saline (PBS) pH 7.4, the slides were incubated with a 1:200 dilution of anti-mouse IgG peroxidase (Sigma Cat no: A9044) in PBS containing $0.2 \%$ bovine serum albumin (Sigma Cat no: A-7034) and 1\% normal human serum. After washing the slides with PBS, they were stained for peroxidase activity with 3.3'-diaminobenzidine-tetrahydrochloride (DAB) (Sigma Cat no: D3939). Counterstaining with hematoxylin was done. Sections were then examined by using a research microscope (Leica DMR, Wetzlar, Germany) and images were obtained by a digital camera (Leica DC500, Wetzlar, Germany).

\section{Results}

\section{Histopathological findings}

In the samples examined the lumina of the affected vessels were completely obliterated and microvessels in intima serving as recanalizing vessels were evident. Varying degrees of infiltrating mononuclear cells in tunica intima were also present in both of the samples. The tunica media was rather thick which is usually considered as a characteristic feature of TAO when compared to other obliterating pathologies like athero- 
Table 1. The specificity, clone name, source and dilutions of primary antibodies used in this study are listed. HLDA WS VIII, Human Leukocyte Differentiation Antigens Workshop VIII; CD, cluster of differentiation.

\begin{tabular}{|c|c|c|c|c|}
\hline Specificity & Clone Name & Antigen Synonyms & Source & Dilution \\
\hline- & HI302 & - & HLDA WS VIII & $1 / 100$ \\
\hline Vimentin & V9 & - & Abcam & $1 / 300$ \\
\hline CD10 (CALLA) & $56 \mathrm{C} 6$ & $\begin{array}{l}\text { Common acute lymphocytic leukemia } \\
\text { antigen }\end{array}$ & Abcam & $1 / 100$ \\
\hline CD11c & Bu15 & Integrin alpha $X$ & Abcam & $1 / 100$ \\
\hline CD19 & LT19 & B-lymphocyte antigen & Abcam & $1 / 100$ \\
\hline $\mathrm{CD} 20$ & L26 & Fc epsilon receptor I beta chain & Abcam & prediluted \\
\hline CD22 (BL-CAM) & RFB4 & B lymphocyte cell adhesion molecule & Millipore & $1 / 100$ \\
\hline CD34 & $\mathrm{BI}-3 \mathrm{C} 5$ & Hematopoietic progenitor cell antigen & Abcam & $1 / 100$ \\
\hline CD44 & F10-44-2 & Hyaluronate receptor & Abcam & $1 / 100$ \\
\hline CD62E & $\mathrm{P} 2 \mathrm{H} 3$ & E-selectin & Millipore & $1 / 200$ \\
\hline CD80 & MABI04 & Activation B7I antigen & Abcam & $1 / 50$ \\
\hline CD90 & AF-9 & Thy I cell surface antigen & Abcam & $1 / 100$ \\
\hline CD104 & ASC-3 & Integrin $\beta 4$ & Millipore & $1 / 100$ \\
\hline CD106 (VCAM1) & $1.4 \mathrm{C} 3$. & Vascular cell adhesion molecule I & Abcam & $1 / 100$ \\
\hline CD116 (CSF2RA) & $4 \mathrm{Hl}$ & $\begin{array}{l}\text { Granulocyte-macrophage colony-stimulating } \\
\text { factor receptor alpha }\end{array}$ & Bio Legend & $1 / 100$ \\
\hline CD117 (c-Kit) & 57A5D8 & Stem cell factor receptor & Abcam & $1 / 300$ \\
\hline CD123 (IL3RA) & $6 \mathrm{H} 6$ & Interleukin 3 receptor alpha chain & Abcam & $1 / 100$ \\
\hline CD132 (IL2RG) & $5 \mathrm{~J} 92$ & Common cytokine receptor gamma chain & LifeSpan BioSciences & $1 / 100$ \\
\hline CD 195 (CCR5) & 1M2D7 & $\mathrm{CC}$ chemokine receptor type 5 & BD Sciences & $1 / 100$ \\
\hline TARC & $6 \mathrm{SN}$ & Thymus and activation-regulated chemokine & Leica Microsystems Inc. & $1 / 30$ \\
\hline
\end{tabular}

sclerosis. Prominent internal elastic lamina also helps to delineate intima and media layers. In addition, the number of microvasculature was determined to be increased also in tunica media. No significant pathological change was observed in tunica adventitia.

\section{Immunohistochemical findings}

Control: In both control stainings (which the primary antibodies were replaced by their non-immune isotypes) no reaction was determined in all layers of affected vessels.

No significant reaction was detected for the following antigens: CD10 (CALLA- zinc metallo-peptidase), CD19, CD20, CD22, CD62E, CD80, CD116 (GMCSF receptor alpha chain), CD132 (IL2RG; common cytokine receptor gamma chain; common gamma) and TARC (Thymus and Activation-Regulated Chemokine).

Reactive antigens and their reactivity pattern are summarized below.

\section{A-Structural/stromal/endothelial antigens}

Vimentin: A weak to moderate reaction was present in the vascular smooth muscle including the tunica media of the artery itself (Fig. 1). Vimentin immunoreactivity helped to reveal all calibers of vasculature in the tissue samples examined. Intimal and adventitial fibroblasts were also reactive for the antigen.

CD104: Weak to moderate expression on the vascular smooth muscle and endothelial layer was observed, though not typically reflecting the linear tissue distribution of this integrin chain along the basal lamina.

CD34: The antigen is well recognized as a hemopoietic stem cell marker and it was strongly expressed by all of the microvascular endothelial cells present in the sections (Figs. 2a and 2b). These vessels were located in intima (recanalizing vessels), media and adventitia of the affected vessel. Reaction to this antigen was clearly restricted to the endothelial lining and revealed how extensive were the newly formed vessels in tunica intima. A significant finding observed by the expression of this antigen was the presence of extensive microvasculature in tunica media (which was somehow surprising being at this extent), in addition to intima and adventitia. This finding was more prominent at a higher magnification in Fig. $2 b$.

CD44: CD44 antigen was expressed by some vascular endothelial cells, fibroblasts in intima, media and 
especially in adventitia and elongated cells (fibroblasts) along internal elastic lamina.

CD90: A moderate to strong reaction was present on fibroblasts but the antigen was also strongly expressed by all of the endothelial cells and vascular smooth muscle of newly formed vasculature in the lumen (Fig. 3).

CD106 (VCAM-1): This antigen was expressed by the microvascular endothelial cells and some mononuclear cells in the samples examined. Those vessels reactive for the antigen were the recanalization vessels in the intima.

HI302 monoclonal antibody (Endothelial cell marker): This endothelial cell antigen revealed the extensive vascular network along the whole thickness of the affected vessel wall (Fig. 4). As most endothelial cell antigens were also weakly reactive with vascular smooth muscle, this antigen reflected a unique sample which was absent on vascular smooth muscle cells.

\section{B-Leukocyte/lymphocyte antigens}

CD11c: CD11c antigen was detected on some cells with dendritic processes and also on blood mononuclear cells in the vessel lumen (Fig. 5). The cells observed in the vessel wall were macrophages; however, some of them may also represent dendritic cells which cannot be excluded.

CD195 (CCR5): This macrophage specific antigen revealed macrophages with their dendritic processes. Such reactive cells were present in all three layers of the vessel wall, but the presence of many reactive cells in tunica media was a bit surprising (Fig. 6).

CD117: Expression of c-KIT (stem cell factor receptor, SCFR) was found only in a few endothelial cells.

CD123: IL3-R alpha chain expression was determined only on the endothelial lining of some small vessels in the sections.

\section{Discussion}

Although the disease is well described about a century ago, we still know little about the mechanisms of the onset and progress of TAO, probably because only a restricted number of samples are available for examination. So far, only several immunohistochemical studies on this immune-induced, tobacco triggered disease were performed. In one of the studies, linear deposition of immunoglobulins and complement factors along the internal elastic lamina and presence of activated macrophages, B- and T-cells especially in the intima of the affected vessels have been demonstrated [17]. Kim et al. have reported that the immunologic injury to the internal elastic lamina is associated with T-lymphocytic infiltration and this might be the initial morphogenetic mechanism of the thrombotic occlusion and organization of medium-sized arteries in TAO [16]. In another study, among the infiltrating cells, Thelper cells outnumbered cytotoxic $\mathrm{T}$ cells and the expression of VCAM-1 as well as iNOS were observed in endothelial cells around the intima or occluded segment [18]. In an immunohistochemical light and electron microscopical study to analyze the expression of TNF $\alpha$, ICAM-1, VCAM-1 and Eselectin in surgical biopsies obtained from femoral and iliac arteries of patients with TAO, it is indicated that endothelial cells are activated in TAO and that vascular lesions are associated with TNF $\alpha$ secretion by tissue-infiltrating inflammatory cells [36]. Kurata et al. presented histological and immunohistochemical characteristics of TAO that would be helpful in a differential diagnosis from arteriosclerosis obliterans (ASO) and thromboembolism [6,7]. In the subset of definite TAO cases, the macrophages, and B- and T-lymphocytes were mostly found in close vicinity to internal elastic lamina and adventitia, often following the recanalizing vessels and vasa vasorum, suggesting that minute vessels and elastic fibers are specific targets of the inflammatory reaction in TAO [7]. It has been suggested that immunovasculitic disorder and dysfunction of the microvascular endothelial cells are the unifying frame of this vaso-occlusive disease, which is superimposed and modified by immune responses to normally hidden antigenic determinants of the vascular intima [6,7]. Nishikimi et al. also postulated that there is a breakdown of the microvascular defense system from the beginning of the disease [37]. In the current study we aimed to determine novel antigens hoping to obtain evidence on the nature of the development of the disease with special regard to inflammatory process and structural changes.

From a structural point of view, both of the samples examined in this study fulfilled the previously reported histopathological characteristics of the disease. Expression patterns of vimentin, CD104 and CD44 reflected the expected features of stromal component organization. One of our most interesting findings was the presence of numerous vessels also in tunica media which is not reported as a distinct histopathological finding. Examining vasculature using endothelial cell reactive antibodies like anti-CD34, HI302 and antiCD90 helped greatly to determine the extent of the vascular network as well as its structural organization. Similar findings were observed in the illustrations of a previous report by Kurata et al [7], however authors did not stress this finding. In our opinion, it is not surprising to have a similar reaction in adjacent compartments of a vessel facing the same local stimuli for angiogenesis and/or vasculogenesis. Moreover, CD90 (Thy-1) was strongly expressed by vasculature and by some stromal cells (fibroblasts and mesenchymal stem 

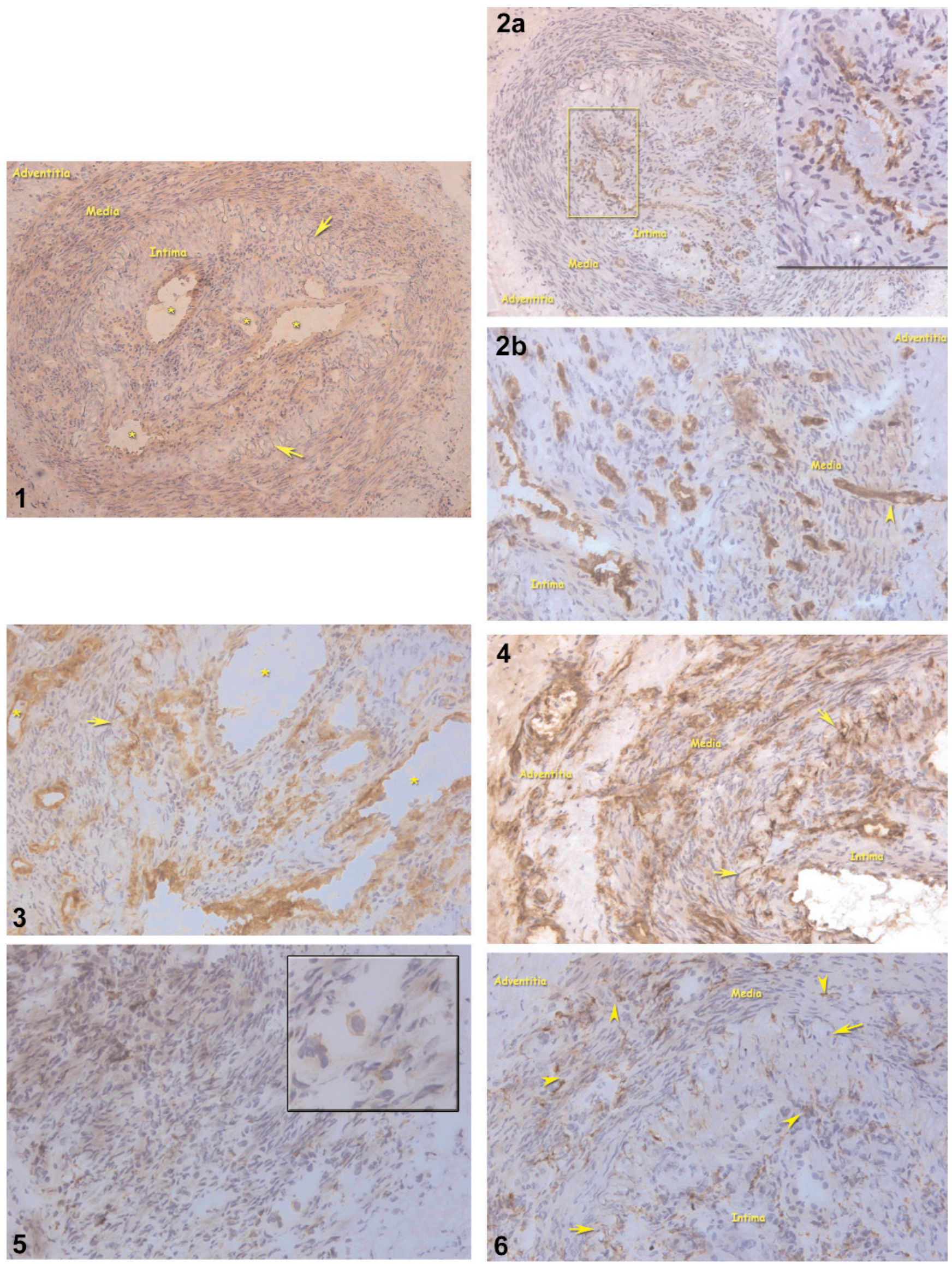
cells?) in the neighboring connective tissue compartments. It is suggested that this glycophosphatidylinositol (GPI)-anchored immunoglobulin family member has a signaling function in various physiological and pathological events including thymocyte maturation, axon regeneration, apoptosis, adhesion, cancer, fibrosis, leukocyte recruitment and angiogenesis. CD90 also helps to characterize mesenchymal stem cell populations [38-44]. In our study, a strong and broad expression of CD90 supports the view that this antigen is involved in the new vessel formation in tunica intima and media of the affected vessels in TAO. It was previously reported that human Thy-1 (CD90) on activated endothelial cells serves as a counterreceptor for the leukocyte integrin Mac-1 (CD11b/CD18) [42]. We examined CD11c, another leukocyte integrin, and a strong expression of this antigen was determined on mononuclear cells in some samples. This finding together with CD90 expression by vascular endothelial cells in the involved tissue suggests that CD11c probably serves as another ligand for leukocyte migration for this antigen in TAO. CD90 may have a role in leukocyte (and/or other cell types) recruitment to the effected site of the vessel. Taken together, both findings suggest that CD90 is at least one of the key molecules involved in the pathogenesis of the disease. Our attempt to find out other antigens like CD106 (VCAM) and CD62E with a similar documented role as CD90 was not fruitful, as CD62E was completely lacking, and CD106 was expressed by the endothelial lining of few vessels and few mononuclear cells. Therefore, these molecules may play roles in the earlier stages of the disease, but probably not after the disease is completely settled down.

High endothelial venules are specific postcapillary venules located in diffuse lymphoid tissue compartments of secondary lymphoid organs and at chronic inflammatory sites, such as the synovial tissues in rheumatoid arthritis [45,46]. In our samples, we did not observe a high endothelial venule, which indicates that continuous and pronounced lymphocyte migration to the lesion side is not present. B cell differentiation maturation and/or activation markers, such as CD10, CD19, CD20 and CD22 were also lacking, suggesting that there is no B cell infiltration and antibody production locally. We also looked for TARC (Thymus and activation regulated chemokine) and CCR5 (CD195) expression to examine if this chemokine and chemokine receptor are involved in this process. TARC is reported to be a chemokine directing migration of $\mathrm{CD} 4+\mathrm{Th} 2$ lymphocytes which suppresses local inflammatory reaction [47]. CCR5 is a receptor for RANTES, MIP- $1 \alpha$ and MIP-1 $\beta$ playing a dominant role in immune reactions like graft versus host disease, multiple sclerosis and rheumatoid arthritis [48-51]. TARC was not present in any of the TAO samples but CCR5 expression was determined on macrophages (some of which may represent dendritic cells). The absence of TARC may be considered as a sign of limited local suppression of inflammation. Similarly, the absence of several cytokine receptors, such as CD116 (GM-CSFR $\alpha$ chain), CD117 (Stem Cell Factor- cKIT receptor), CD123 (IL3-R $\alpha-$ chain), CD132 (IL-2R $\gamma$ chain: common $\gamma$ chain receptor for cytokine receptors) suggests that they are not involved in this process. On the other hand, the protein expression of CCR5 suggests a possible role for this receptor in TAO. CD80, a co-regulator of T cell activation with CD86, is involved in the alloactivation of $\mathrm{T}$ cells and known to play a critical role in autoimmune, humoral, and transplant responses. It is expressed on activated $\mathrm{B}$ cells, activated $\mathrm{T}$ cells and macrophages [52-55]. CD80 was also absent in TAO samples examined in this study.

In conclusion, in addition to the major involvement site intima, the involvement of tunica media is critical, regarding new vessel formation and macrophage / den-

Fig. 1. In a frozen section through dorsalis pedis artery the lumen of the vessel is seen to be completely obliterated due to TAO. Intact internal elastic lamina (arrows) indicates the border of tunica intima. Several sections of varying sizes of recanalizing vessels in the lumen of the vessel are observed (asterix). Vascular smooth muscle of both the artery itself and the newly developed recanalizing vessels is reactive for vimentin. Intimal and adventitial fibroblasts are also reactive. Indirect immunoperoxidase - hematoxylin counterstained, original magnification $\times 10$. Fig. 2. Immunohistochemical staining for CD34 antigen: (a) Strong CD34 reactivity on the endothelial lining of all vasculature is observed. Inset: Higher magnification of the area consisting of internal elastic lamina at lower left diagonal; several vessels in intima are evident. Indirect immunoperoxidase - hematoxylin counterstained, original magnification $\times 10$; inset $\times 20$. (b) Expression of the same antigen at a higher magnification. Intima consists of numerous recanalizing vessels. Internal elastic lamina delineates intima and media. More interesting finding is the presence of numerous vessels also in media. One of them is observed extending from adventitia into media (arrow head). Indirect immunoperoxidase - hematoxylin counterstained, original magnification $\times 20$. Fig. 3. A broader reactivity pattern for CD90 antigen is detected. In addition to endothelial cells, vascular smooth muscle and some fibroblasts are also reactive. Asterix: lumina of the vasculature. Arrow: internal elastic lamina. Indirect immunoperoxidase - hematoxylin counterstained, original magnification $\times 10$. Fig. 4. Immunoreactivity of HI302 mAb. Strong reactivity with almost all vascular endothelial cells is observed. Arrows: internal elastic lamina. Indirect immunoperoxidase - hematoxylin counterstained, original magnification $\times 10$. Fig. 5. Cells with dendritic processes are reactive (moderate to strong) for CD11c antigen. A large mononuclear cell in the lumen of a small vessel also exhibits a strong membranous reaction (inset). Indirect immunoperoxidase - hematoxylin counterstained, original magnification $\times 10$ (inset original magnification $\times 40$ ). Fig. 6. Cells with processes are reactive for CD195 antigen detected by 1M2D7 monoclonal antibody. As the antigen is specific to macrophages it is somehow surprising to observe many reactive cells in tunica media (arrow heads). Arrow: internal elastic lamina. Indirect immunoperoxidase - hematoxylin counterstained, original magnification $\times 10$. 
dritic cell infiltration presumably participating in the complex pathogenesis of the disease. Among all the screened antigens, CD90 (Thy1) represents the most prominent one. Taken together with the expression of CD11c on macrophages/dendritic cells it can be suggested that this molecule pair is possibly involved in cellular recruitment to the affected vessel wall. CCR5 expression also suggests a role for this chemokine in this process. The present findings provide preliminary data indicating further examinations in greater detail will be valuable.

\section{References}

[1] Buerger L. Thromboangiitis obliterans: a study of the vascular lesions leading to presenile spontaneous gangrene. Am J Med Sci. 1908;136:567-80.

[2] Shionoya S. What is Buerger's disease? World J Surg. 1983;7(4):544-51.

[3] Cutler DA, Runge MS. 86 years of Buerger's disease--what have we learned? Am J Med Sci. 1995;309(2):74-5.

[4] Olin JW, Shih A. Thromboangiitis obliterans (Buerger's disease). Curr Opin Rheumatol. 2006;18(1):18-24.

[ 5] Mills JL Sr. Buerger's disease in the 21st century: diagnosis, clinical features, and therapy. Semin Vasc Surg. 2003;16(3):179-89.

[ 6] Kurata A, Franke FE, Machinami R, Schulz A. Thromboangiitis obliterans: classic and new morphological features. Virchows Arch. 2000;436(1):59-67.

[7] Kurata A, Machinami R, Schulz A, Fukayama M, Franke FE. Different immunophenotypes in Buerger's disease. Pathol Int. 2003;53(9):608-15.

[8] Lie JT. The rise and fall and resurgence of thromboangiitis obliterans (Buerger's disease). Acta Pathol Jpn. 1989;39(3):153-8.

[9] Lie JT. Thromboangiitis obliterans (Buerger's disease) in women. Medicine (Baltimore). 1987;66:65-72.

[10] Olin JW, Young JR, Graor RA, Ruschhaupt WE, Bartholomew JR. The changing clinical spectrum of thromboangiitis obliterans (Buerger's disease). Circulation. 1990;82(Suppl IV):3-8.

[11] Calguneri M, Ozturk MA, Ay H et al. Buerger's disease with multisystem involvement. A case report and a review of the literature. Angiology. 2004;55(3):325-8.

[12] Cho YP, Kang GH, Han MS et al. Mesenteric involvement of acute-stage Buerger's disease as the initial clinical manifestation: report of a case. Surg Today. 2005;35(6):499-501.

[13] Hong TE, Faxon DP. Coronary artery disease in patients with Buerger's disease. Rev Cardiovasc Med. 2005;6(4):222-6.

[14] de Paiva Magalhaes E, Trevisan M, Mochizuki M, Sachetto Z, Samara AM, Fernandes SR. Intestinal ischemia as a single manifestation of thromboangiitis obliterans-a case report. Angiology. 2005;56(6):789-92.

[15] Shionoya S. Diagnostic criteria of Buerger's disease. Int $J$ Cardiol. 1998;66 Suppl 1:S243-5.

[16] Kim EJ, Cho BS, Lee TS, Kim SJ, Seo JW. Morphologic change of the internal elastic lamina in Buerger's disease. $J$ Korean Med Sci. 2000;15(1):44-8.

[17] Kobayashi M, Ito M, Nakagawa A, Nishikimi N, Nimura Y. Immunohistochemical analysis of arterial wall cellular infiltration in Buerger's disease (endarteritis obliterans). $J$ Vasc Surg. 1999;29:451-8.

[18] Lee T, Seo JW, Sumpio BE, Kim SJ. Immunobiologic analysis of arterial tissue in Buerger's disease. Eur J Vasc Endovasc Surg. 2003;25(5):451-7.
[19] Tanaka K. Pathology and pathogenesis of Buerger's disease. Int J Cardiol. 1998;66 Suppl 1:S237-42.

[20] Gore I, Burrows S. A reconsideration of the pathogenesis of Buerger's disease. Am J Clin Pathol. 1958;29(4):319-30.

[21] McLoughlin GA, Helsby CR, Evans CC, Chapman DM. Association of HLA-A9 and HLA-B5 with Buerger's disease. Br Med J. 1976;2:1165-6.

[22] Kimura A, Kobayashi Y, Takahashi M et al. MICA gene polymorphism in Takayasu's arteritis and Buerger's disease. Int $J$ Cardiol. 1998;66 Suppl 1:S107-13.

[23] Avcu F, Akar E, Demirkiliç U, Yilmaz E, Akar N, Yalçin A. The role of prothrombotic mutations in patients with Buerger's disease. Thromb Res. 2000;100(3):143-7.

[24] Papa M, Bass A, Adar R et al. Autoimmune mechanisms in thromboangiitis obliterans (Buerger's disease): the role of tobacco antigen and the major histocompatibility complex. Surgery. 1992;111(5):527-31.

[25] Zheng P, Fu PB, Wang WC et al. Immunological studies on thromboangiitis obliterans. Chin Med $J$ (Engl). 1989;102(2):129-36.

[26] de Godoy JM, Braile DM, Godoy MF. Buerger's disease and anticardiolipin antibodies: a worse prognosis? Clin Appl Thromb Hemost. 2002;8(1):85-6.

[27] Eichhorn J, Sima D, Lindschau C et al. Antiendothelial cell antibodies in thromboangiitis obliterans. $\mathrm{Am} \mathrm{J} \mathrm{Med} \mathrm{Sci.}$ 1998;315(1):17-23

[28] Adar R, Papa MZ, Halpern Z et al. Cellular sensitivity to collagen in thromboangiitis obliterans. $N$ Engl J Med. 1983;308:1113-16.

[29] Hada M, Sakihama T, Kamiya K, Tasaka K, Ueno A. Cellular and humoral immune responses to vascular components in thromboangiitis obliterans. Angiology. 1993;44(7):53340.

[30] Gulati SM, Saha K, Kant L, Thusoo TK, Prakash A. Significance of circulatory immune complexes in thromboangiitis obliterans (Buerger's disease). Angiology. 1984;35(5):27681.

[31] Roncon de Albuquerque R, Delgado L, Correia P, Torrinha JF, Serrao D, Braga A. Circulating immune complexes in Buerger's disease. Endarteritis obliterans in young men. J Cardiovasc Surg (Torino). 1989;30(5):821-5.

[32] Horsch AK, Brechemier D, Robert L, Horsch S. Anti-elastin antibodies in thrombangiitis obliterans (Winiwarter-Buerger disease). Verh Dtsch Ges Inn Medical. 1977;83:1758-61.

[33] Bokarewa M, Baranov A, Nassonov E, Robert L. Elastin degradation in systemic vasculitis. Pathol Biol (Paris). 1996;44(4):254-8.

[34] Slavov ES, Stanilova SA, Petkov DP, Dobreva ZG. Cytokine production in thromboangiitis obliterans patients: new evidence for an immune-mediated inflammatory disorder. Clin Exp Rheumatol. 2005;23(2):219-26.

[35] Dijkstra CD, Döpp EA, Joling P, Kraal G. The heterogeneity of nuclear phagocytes in lymphoid organs: Distinct macrophage subpopulations in the rat recognized by monoclonal antibodies ED1, ED2, ED3. Immunology. 1985;54:389-99.

[36] Halacheva K, Gulubova MV, Manolova I, Petkov D. Expression of ICAM-1, VCAM-1, E-selectin and TNF-alpha on the endothelium of femoral and iliac arteries in thromboangiitis obliterans. Acta Histochem. 2002;104(2):177-84.

[37] Nishikimi N, Sakurai T, Shionoya S, Oshima M. Microcirculatory characteristics in patients with Buerger's disease. Angiology. 1992;43(4):312-9.

[38] Schäfer H, Bartels T, Hahn G, Otto A, Burger R. T-cell-activating monoclonal antibodies, reacting with both leukocytes and erythrocytes, recognize the guinea pig Thy-1 differentiation antigen: characterization and cloning of guinea pig CD90. Cell Immunol. 1999;197(2):116-28. 
[39] Hueber AO, Pierres M, He HT. Thy-1 functions as a recognition/signaling molecule during mouse T lymphocyte development. Braz J Med Biol Res. 1994;27(2):275-81.

[40] Rege TA, Hagood JS. Thy-1 as a regulator of cell-cell and cell-matrix interactions in axon regeneration, apoptosis, adhesion, migration, cancer, and fibrosis. FASEB $J$. 2006;20(8):1045-54

[41] Rege TA, Hagood JS. Thy-1, a versatile modulator of signaling affecting cellular adhesion, proliferation, survival, and cytokine/growth factor responses. Biochim Biophys Acta. 2006;1763(10):991-9.

[42] Wetzel A, Chavakis T, Preissner KT et al. Human Thy-1 (CD90) on activated endothelial cells is a counterreceptor for the leukocyte integrin Mac-1 (CD11b/CD18). J Immunol. 2004;172(6):3850-9.

[43] Oishi K, Ito-Dufros Y. Angiogenic potential of CD44+ CD90+ multipotent CNS stem cells in vitro. Biochem Biophys Res Commun. 2006;349(3):1065-72.

[44] Dominici M, Le Blanc K, Mueller I et al. Minimal criteria for defining multipotent mesenchymal stromal cells. The International Society for Cellular Therapy position statement. Cytotherapy. 2006;8(4):315-7.

[45] Miyasaka M, Tanaka T. Lymphocyte trafficking across high endothelial venules: dogmas and enigmas. Nat Rev Immunol. 2004;4(5):360-70.

[46] Cavender D, Haskard D, Yu CL et al. Pathways to chronic inflammation in rheumatoid synovitis. Fed Proc. 1987;46(1):113-7.

[47] Imai T, Nagira M, Takagi S et al. Selective recruitment of CCR4-bearing Th2 cells toward antigen-presenting cells by the $\mathrm{CC}$ chemokines thymus and activation-regulated chemokine and macrophage-derived chemokine. Int Immunol. 1999;11(1):81-8.
[48] Raport CJ, Gosling J, Schweickart VL, Gray PW, Charo IF. Molecular cloning and functional characterization of a novel human CC chemokine receptor (CCR5) for RANTES, MIP1beta, and MIP-1alpha. J Biol Chem. 1996;271(29):17161-6.

[49] Wysocki CA, Burkett SB, Panoskaltsis-Mortari A et al. Differential roles for CCR5 expression on donor T cells during graft-versus-host disease based on pretransplant conditioning. J Immunol. 2004;173(2):845-54.

[50] Balashov KE, Rottman JB, Weiner HL, Hancock WW. CCR5(+) and CXCR3 $(+) \mathrm{T}$ cells are increased in multiple sclerosis and their ligands MIP-1alpha and IP-10 are expressed in demyelinating brain lesions. Proc Natl Acad Sci USA. 1999;96(12):6873-8.

[51] Nissinen R, Leirisalo-Repo M, Tiittanen M et al. CCR3, CCR5, interleukin 4, and interferon-gamma expression on synovial and peripheral $\mathrm{T}$ cells and monocytes in patients with rheumatoid arthritis. J Rheumatol. 2003;30(9):1928-34.

[52] Slavik JM, Hutchcroft JE, Bierer BE. CD28/CTLA-4 and CD80/CD86 families: signaling and function. Immunol Res. 1999;19(1):1-24.

[53] Lumsden JM, Williams JA, Hodes RJ. Differential requirements for expression of CD80/86 and CD40 on B cells for Tdependent antibody responses in vivo. $J$ Immunol. 2003;170(2):781-7.

[54] Kurokohchi K, Masaki T, Himoto T et al. Usefulness of liver infiltrating CD86-positive mononuclear cells for diagnosis of autoimmune hepatitis. World $J$ Gastroenterol. 2006;12(16):2523-9.

[55] Vincenti F. Costimulation blockade in autoimmunity and transplantation. J Allergy Clin Immunol. 2008;121(2):299306.

Submitted: 18 September, 2009 Accepted after reviews: 12 January, 2010 